\title{
Blood Glucose Concentration in the Perinatal Period
}

\author{
GEORGE RUSSELL * and ERIC McKAY \\ From the Royal Aberdeen Hospital for Sick Children, and the Department of Child Health, University of Aberdeen
}

Low blood sugar concentrations are common in infants, and concentrations which in the adult would be considered pathologically low may be physiological in the newborn in whom hypoglycaemia is not necessarily associated with symptoms (Ketteringham and Austin, 1938; McKittrick, 1940; Hanley and Horn, 1943; Norval, Kennedy, and Berkson, 1949; Wachter, 1949; Pedersen, 1952; Desmond, 1953; Lowrey, Graham, and Tsao, 1954; Hartmann, 1955; Haworth and Ford, 1960; Kaye, Davidson, Williams, Kumagai, and Picou, 1961 ; Melichar, Novák, Hahn, and Koldovský, 1964; Neligan, 1964a; Stur, 1964; Hjelm and Sjölin, 1965).

Symptomatic hypoglycaemia has been described in infants with lesions which might be expected to lower the blood sugar concentration (Mason and Andersen, 1941; Sherman, 1947), and Hartmann and Jaudon (1937) attributed to hypoglycaemia certain symptoms in infants of diabetic mothers, though Pedersen (1952), Lowrey et al. (1954), and Farquhar (1956) found equally low blood sugar concentrations in patients with no symptoms. As early as 1934, Holman and Mathieu suggested that the blood sugar might fall to dangerously low concentration in infants of toxaemic mothers, but it is only since Cornblath, Odell, and Levin (1959) revived interest in such cases that symptomatic hypoglycaemia in the neonatal period has been accepted as a definite and not uncommon entity.

The association between foetal malnutrition and neonatal hypoglycaemia has been described by Brown and Wallis (1963) and by Neligan, Robson, and Watson (1963). Cornblath now feels that poor foetal growth was the most important aetiological factor in the cases of hypoglycaemia which he and his colleagues originally attributed to maternal toxaemia (Cornblath et al., 1959; Neligan, 1964b). Even in asymptomatic babies with the foetal mal-

Received February 4, 1966.

* Present address: Department of Pediatrics, University of Colorado, Denver, Colorado, U.S.A. nutrition syndrome, low blood glucose concentrations have been found (Melichar et al., 1964), and Smallpeice and Davies (1964) found that the mean of the lowest blood sugar concentrations in 13 infants who were below expected birth weight was significantly lower than in other premature infants.

The administration of glucose by intravenous injection is well established in the management of neonatal hypoglycaemia (Neligan, 1965), and oral therapy using laevulose has also been successful (Tynan and Haas, 1963). The use of glucocorticoids and corticotrophin is subject to controversy. Cornblath et al. (1959) administered corticotrophin and cortisone to one patient and, in a further paper, such treatment was strongly recommended (Cornblath, Wybregt, Baens, and Klein, 1964). Neligan et al. (1963) stated that 'the response to glucocorti- ? coids is . . good and merits further investigation'. On the other hand, Brown and Wallis (1963) suspected that hypoglycaemia might be associated with depleted glycogen stores, a suspicion borne out by Shelley's (1964) finding of 'unexpectedly low' tissue carbohydrate concentrations in infants who were small for duration of gestation, and they, therefore, avoided the use of glucocorticoids and corticotrophin on the grounds that these drugs might aggravate such depletion. Cortisone acetate had no effect on the hypoglycaemia of 4 infants studied by Stur (1964), but Creery (1963) stated that oral glucose combined with $25 \mathrm{mg}$. hydrocortisone by intramuscular injection was a safe and reliable means of treating neonatal hypoglycaemia, though oral glucose alone was ineffective.

Smallpeice and Davies (1964) believed that early feeding of premature infants prevented neonatal hypoglycaemia, but Haworth and Ford (1963) found that early feeding of premature infants had no significant effect on blood sugar concentration during the first 5 days of life.

In the present paper, observations on the relation between maternal venous and umbilical venous blood glucose concentrations at birth are reported, 
with particular reference to the possibility that duration of gestation independently of birth weight might influence that relation. The influence of various regimens on the postnatal blood glucose concentrations of infants who were under expected birthweight for the period of gestation (hereafter referred to as 'underweight') is described, and the effect on capillary blood glucose concentration of warming the extremity from which the blood is taken is reported.

\section{Methods}

Estimation of blood glucose concentration. Glucose concentration was estimated by the zinc hydroxide-glucose oxidase method of Hjelm and de Verdier (1963), using $0 \cdot 1 \mathrm{ml}$. plasma or whole blood for each determination, and reading the absorbancy at $450 \mathrm{~m} \mu$ in a Unicam SP 400 spectrophotometer. The estimations on umbilical cord and maternal blood at delivery were carried out on plasma from heparinized blood, and the estimations on postnatal specimens were on whole blood.

The accuracy of the method was assessed by estimations on 28 pairs of separately pipetted and analysed whole blood specimens with glucose concentrations ranging from 6 to $106 \mathrm{mg}$. $/ 100 \mathrm{ml}$. The results were evaluated by the method suggested by Cornblath, Levin, and Gordon (1956). For each pair, the difference of the two determinations from their mean was calculated, and from these values the standard deviation (SD) of the individual differences was found to be $2.49 \mathrm{mg}$. $/ 100 \mathrm{ml}$. The standard error (SE) of the difference between any two determinations is $\sqrt{2} \times \mathrm{SD}$ of the individual differences, or $3.5 \mathrm{mg} . / 100 \mathrm{ml}$. Hence, a difference between paired results (e.g. blood from warmed and unwarmed feet) of $2 \mathrm{SE}$ of the difference (i.e. $7.0 \mathrm{mg}$./ $100 \mathrm{ml}$.) is significant in $95 \%$ of cases. In analysing the results, a difference of $7.5 \mathrm{mg} . / 100 \mathrm{ml}$. has been accepted as significant. The corresponding value used by Cornblath et al. (1956) was $4.0 \mathrm{mg}$. $/ 100 \mathrm{ml}$.

\section{Case Selection}

Unselected cases at birth. Glucose concentration was estimated in plasma obtained from the umbilical vein and from a maternal antecubital vein at the moment of birth in 63 unselected deliveries. Of these mothers, 45 had regular menstrual cycles ( $28 \pm 4$ days) and were able to state with certainty the date of the last menstrual period. One mother was a diabetic. There was no case of severe maternal toxaemia but 3 mothers had mild preeclampsia and one had essential hypertension.

Postnatal study of 'underweight' infants. The 30 infants in this trial were selected on the criteria that their mothers had regular menstrual cycles and could state with certainty the dates of their last menstrual periods, and that the birthweights of the infants fell below the third percentile for the period of gestation. The percentile calculations were based on data obtained from 14,156 single legitimate births in the City of Aberdeen from 1956 to 1960 inclusive (Table I).
Excluded from the trial were multiple births, deformed infants, infants weighing over $5 \mathrm{lb} .8 \mathrm{oz}$. $(2500 \mathrm{~g}$.) (for administrative reasons), and infants with gestational ages of less than 36 weeks, the data available being inadequate for accurate percentile calculations below this period of gestation. One infant was removed from the trial because he began to vomit at the age of 18 hours.

The infants were allocated by predetermined random selection to 3 groups.

\section{TABLE I}

Third Percentile for Birthweight at Various
Durations of Gestation

(based on data from 14,156 single legitimate births)

\begin{tabular}{c|c|c}
\hline $\begin{array}{c}\text { Duration of } \\
\text { Gestation } \\
\text { (wk.) }\end{array}$ & Third Percentile for Birthweight \\
\cline { 2 - 3 } & (oz.) & (g.) \\
\hline 36 & $56 \cdot 75$ & 1606 \\
37 & $67 \cdot 25$ & 1903 \\
38 & $75 \cdot 5$ & 2137 \\
39 & $83 \cdot 0$ & 2349 \\
40 & $89 \cdot 25$ & 2526 \\
\hline
\end{tabular}

Low calorie group. These infants received no feeds for the first 24 hours of life and were then fed every 3 hours during the next 24 hours with quarter-strength half-cream National Dried Milk reconstituted using 5\% glucose in water. No other sugar was added. The volume given was $2 \mathrm{ml} . / \mathrm{lb}$. (4.4 ml. $/ \mathrm{kg}$.) body weight per feed, giving an intake during the second 24 hours of $5 \cdot 4$ calories $/ \mathrm{lb}$. (11.9 calories $/ \mathrm{kg}$.) of which $74 \%$ were derived from carbohydrate. During the third 24 hours of life the feeds were half-strength half-cream National Dried Milk (reconstituted as above) $3 \mathrm{ml} . / \mathrm{lb}$. $(6.6 \mathrm{ml} . / \mathrm{kg}$.) per feed, giving an intake of 11.5 calories/lb. $(25 \cdot 4$ calories/ kg.) during the third day, of which $63 \%$ were derived from carbohydrate. No other treatment was given to these infants.

High calorie group. These infants received no feeds for the first 24 hours of life. During the next 24 hours their feeds consisted of $10 \%$ glucose given at the rate of $4 \mathrm{ml} . / \mathrm{lb}$. $(8.8 \mathrm{ml}$. $/ \mathrm{kg}$.) body weight every three hours, a total calorie intake of $12 \cdot 8 / \mathrm{lb}$. $(28 \cdot 2$ calories $/ \mathrm{kg}$.) during the second day, all derived from carbohydrate. During the third 24 hours of life the feeds consisted of half-cream National Dried Milk reconstituted with $10 \%$ glucose in a volume of $4 \mathrm{ml}$./lb. every 3 hours. The total calorie intake during the third day was $21 \cdot 8 / \mathrm{lb}$. $(48 \cdot 1$ calories/ $\mathrm{kg}$.) of which $73 \%$ were derived from carbohydrate.

Hydrocortisone group. These infants had exactly the same feeding regimen as the infants in the high calorie diet group, but in addition they were given hydrocortisone acetate by intramuscular injection in a dosage of $25 \mathrm{mg}$. at the age of 24 hours and $12.5 \mathrm{mg}$. at the age of 36 hours.

Capillary blood for glucose estimation was taken from a heel-stab from each infant at 12-hourly intervals from 
the age of 12 hours to the age of 72 hours. The limb used for obtaining blood was not specially warmed, but the infants were all in incubators or warm nurseries and had no obvious peripheral circulatory stasis. It will be shown below that a highly significant positive correlation existed between the glucose concentrations of blood from warmed and unwarmed feet (though significant differences were present between individual paired concentrations).

Study of capillary glucose concentrations in blood from unwarmed and warmed feet. During the course of the above studies and in other infants in whom glucose concentration was being estimated for various reasons, the opportunity was taken to compare the glucose concentration in capillary blood from an unwarmed foot with that collected immediately afterwards from the other foot which had been warmed for 1 minute in water at $100^{\circ} \mathrm{F} .\left(37 \cdot 8^{\circ} \mathrm{C}\right.$.). To obviate any bias that might have been produced by local circulatory abnormalities, alternate feet were used for 'cold' specimens. In these infants there was no apparent peripheral circulatory stasis, and all were nursed in incubators or warmed cots. In all, 57 pairs of blood specimens were obtained.

In 4 instances blood samples were taken in quick succession from (a) a catheter introduced through the umbilical artery (for other investigations), (b) an unwarmed foot, and (c) a warmed foot.

\section{Results \\ Unselected cases at birth}

63 unselected cases. In the 63 unselected cases the mean concentration of glucose in the maternal venous plasma was $123.1 \mathrm{mg} . / 100 \mathrm{ml}$. $(S D=35 \cdot 8$ mg. $/ 100 \mathrm{ml}$.) and in the umbilical venous plasma was $83.2 \mathrm{mg} . / 100 \mathrm{ml}$. ( $\mathrm{SD}=29.8 \mathrm{mg} . / 100 \mathrm{ml}$.). The mean difference in glucose concentration was $39 \cdot 8 \mathrm{mg} . / 100 \mathrm{ml}$. $(S D=27.8 \mathrm{mg} . / 100 \mathrm{ml}$.).

The correlation between the glucose concentrations in the maternal venous plasma $(M)$ and in the umbilical venous plasma (U) was highly significant $\left(r_{\mathrm{MU}}=0.649 ; \mathrm{p}<0.001\right)$. There was a positive correlation between the sum (S) of maternal venous and umbilical venous plasma glucose concentrations and their difference (D), but this was not statistically significant $\left(\mathrm{r}_{\mathrm{gD}}=+0.238 ; 0.1>\mathrm{p}>0.05\right)$.

45 cases with gestation of known duration. In these cases the mean maternal umbilical venous plasma glucose concentration difference was $41.6 \mathrm{mg} . / 100$ $\mathrm{ml}$. (SD $=27.8 \mathrm{mg} . / 100 \mathrm{ml}$.).

There was a statistically significant positive correlation between duration of gestation (G) and glucose difference (D) $\left(r_{G D}=+0.337 ; 0.05>p\right.$ $>0.02)$ and a positive correlation which was not significant between birthweight $(W)$ and glucose difference $\left(r_{\mathrm{WD}}=+0.237 ; \mathrm{p}>0 \cdot 1\right)$.
Although the glucose concentration difference was more closely related to duration of gestation than to birth weight, the partial correlation coefficient for glucose concentration difference and duration of gestation, with birth weight constant, was not significant $\left(r_{D G . W}=0 \cdot 248 ; p=0 \cdot 1\right)$.

Postnatal study of 'underweight' infants. The blood glucose concentrations in the three groups of infants described above are shown in Table II.

In the low calorie group the blood glucose concentration fell slightly between 12 and 72 hours, giving a pooled regression coefficient for the 10 infants of -0.72 , the linear component of this regression being just significant $(p<0.05)$. In the high calorie group the blood glucose concentration showed a clear tendency to increase with time; the pooled regression coefficient for this group was $+1 \cdot 56$, and the linear component of the regression was highly significant $(p<0.001)$. There was a significant difference $(p<0.05)$ between the pooled regression coefficients for these two groups.

The pooled regression coefficient of +0.65 for the hydrocortisone group was not significant $(p \gg$ $0 \cdot 05$ ), and it was not possible to compare this group with the low and high calorie groups. In the hydrocortisone group an apparent peak in glucose concentration at 36 hours was not significant when the 36-hour concentrations were compared with those at 24 hours and 48 hours by a ' $t$ ' test for difference in pairs (for rise, $t=1 \cdot 153,0 \cdot 3>p>$ $0 \cdot 2$; for fall, $t=2 \cdot 242,0 \cdot 1>p>0 \cdot 05)$.

One infant (low calorie, Case 5A) developed clinical evidence of hypoglycaemia: at the age of $\mathbf{7 2}$ hours he was found to be limp and apathetic. His blood glucose concentration at that point was $4 \mathrm{mg}$./ $100 \mathrm{ml}$. , and he responded to intravenous glucose therapy.

Capillary blood glucose concentration from warmed and unwarmed feet. The mean glucose concentration in blood from the warmed feet was $44.0 \mathrm{mg} . / 100 \mathrm{ml}$., and that in blood from the unwarmed feet was $2.8 \mathrm{mg}$. $/ 100 \mathrm{ml}$. lower. Over-all there was a highly significant correlation between the values in the two groups $(r=+0 \cdot 871$, $p<0.001)$, while the paired results differed significantly $(t=2 \cdot 01,0.05>p>0.02)$.

In 35 cases the glucose concentration was higher in blood from the warmed foot (average difference $=7.06 \mathrm{mg} . / 100 \mathrm{ml}$.; SD $=4.39 \mathrm{mg} . / 100 \mathrm{ml}$.); in 19 it was higher in blood from the unwarmed foot (average difference $=3.91 \mathrm{mg} . / 100 \mathrm{ml}$.; $\mathrm{SD}=1.98$ $\mathrm{mg} . / 100 \mathrm{ml}$.), and in 3 the concentrations were equal.

Accepting as significant a difference of $7.5 \mathrm{mg} . /$ 
TABLE II

Blood Glucose Concentrations from 12 to 72 Hours of Life in Three Groups of Underweight Infants

\begin{tabular}{|c|c|c|c|c|c|c|c|}
\hline \multirow{3}{*}{$\begin{array}{l}\text { Case } \\
\text { No. }\end{array}$} & \multicolumn{6}{|c|}{ Glucose Concentration (mg./100 ml.) } & \multirow{3}{*}{$\begin{array}{l}\text { Regression } \\
\text { Coefficient }\end{array}$} \\
\hline & \multicolumn{6}{|c|}{ Age (hr.) } & \\
\hline & 12 & 24 & 36 & 48 & 60 & 72 & \\
\hline $\begin{array}{c}1 \mathrm{~A} \\
2 \mathrm{~A} \\
3 \mathrm{~A} \\
4 \mathrm{~A} \\
5 \mathrm{~A} \\
6 \mathrm{~A} \\
7 \mathrm{~A} \\
8 \mathrm{~A} \\
9 \mathrm{~A} \\
10 \mathrm{~A}\end{array}$ & $\begin{array}{l}41 \\
52 \\
34 \\
52 \\
40 \\
59 \\
41 \\
54 \\
38 \\
41\end{array}$ & $\begin{array}{l}48 \\
51 \\
36 \\
52 \\
32 \\
66 \\
32 \\
36 \\
63 \\
36\end{array}$ & $\begin{array}{c}A . L o \\
50 \\
57 \\
43 \\
45 \\
31 \\
52 \\
35 \\
45 \\
58 \\
37\end{array}$ & $\begin{array}{c}\text { Group } \\
54 \\
57 \\
29 \\
36 \\
18 \\
68 \\
20 \\
36 \\
54 \\
36\end{array}$ & $\begin{array}{r}-45 \\
20 \\
47 \\
9 \\
49 \\
36 \\
34 \\
61 \\
28\end{array}$ & $\begin{array}{r}54 \\
59 \\
18 \\
43 \\
4 \\
46 \\
50 \\
25 \\
52 \\
50\end{array}$ & $\begin{array}{l}+2 \cdot 473 \\
+1.743 \\
-4.057 \\
-1.971 \\
-7.486 \\
-2.857 \\
+1.200 \\
-4.571 \\
+1.714 \\
+0.571\end{array}$ \\
\hline Mean & $45 \cdot 2$ & $45 \cdot 2$ & $45 \cdot 3$ & $40 \cdot 8$ & $36 \cdot 6$ & $40 \cdot 1$ & \\
\hline $\begin{array}{r}1 \mathbf{B} \\
2 \mathbf{B} \\
3 \mathbf{B} \\
4 \mathbf{B} \\
5 \mathbf{B} \\
6 \mathrm{~B} \\
7 \mathbf{B} \\
8 \mathrm{~B} \\
9 \mathrm{~B} \\
10 \mathrm{~B}\end{array}$ & $\begin{array}{l}51 \\
40 \\
52 \\
30 \\
69 \\
43 \\
20 \\
39 \\
26 \\
58\end{array}$ & $\begin{array}{l}62 \\
45 \\
43 \\
36 \\
45 \\
43 \\
21 \\
41 \\
24 \\
74\end{array}$ & $\begin{array}{c}\text { B. Hig } \\
53 \\
65 \\
37 \\
27 \\
59 \\
35 \\
33 \\
40 \\
19 \\
69\end{array}$ & $\begin{array}{c}\text { Groupt } \\
37 \\
55 \\
61 \\
60 \\
51 \\
35 \\
40 \\
45 \\
100\end{array}$ & $\begin{array}{l}71 \\
52 \\
55 \\
62 \\
50 \\
54 \\
35 \\
54 \\
40 \\
51\end{array}$ & $\begin{array}{l}73 \\
62 \\
52 \\
55 \\
60 \\
39 \\
48 \\
55 \\
63\end{array}$ & $\begin{array}{l}+4 \cdot 244 \\
+2.943 \\
+1.543 \\
+8.900 \\
+1.542 \\
+4.094 \\
+3.971 \\
+2.400 \\
+6.257 \\
-0.371\end{array}$ \\
\hline Mean & $42 \cdot 8$ & $43 \cdot 3$ & $43 \cdot 7$ & $53 \cdot 8$ & $52 \cdot 4$ & $56 \cdot 3$ & \\
\hline $\begin{array}{r}1 \mathrm{C} \\
2 \mathrm{C} \\
3 \mathrm{C} \\
4 \mathrm{C} \\
5 \mathrm{C} \\
6 \mathrm{C} \\
7 \mathrm{C} \\
8 \mathrm{C} \\
9 \mathrm{C} \\
10 \mathrm{C}\end{array}$ & $\begin{array}{l}63 \\
58 \\
43 \\
57 \\
66 \\
24 \\
29 \\
55 \\
23 \\
65\end{array}$ & $\begin{array}{l}69 \\
65 \\
56 \\
25 \\
83 \\
87 \\
30 \\
55 \\
16 \\
51\end{array}$ & 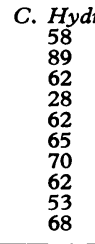 & $\begin{array}{c}\text { Group } \\
55 \\
44 \\
68 \\
34 \\
58 \\
34 \\
43 \\
66 \\
40 \\
51\end{array}$ & $\begin{array}{l}73 \\
56 \\
45 \\
39 \\
75 \\
62 \\
54 \\
52 \\
-\end{array}$ & $\begin{array}{l}67 \\
47 \\
43 \\
61 \\
72 \\
76 \\
60 \\
59 \\
44 \\
60\end{array}$ & $\begin{array}{l}+0.829 \\
+3.630 \\
-0.771 \\
+1.943 \\
+0.057 \\
+4.800 \\
+5.714 \\
+0.429 \\
+5.054 \\
-0.608\end{array}$ \\
\hline Mean & $48 \cdot 3$ & $53 \cdot 7$ & $61 \cdot 7$ & $49 \cdot 3$ & 57 & $58 \cdot 9$ & \\
\hline
\end{tabular}

$\star$ Pooled regression coefficient $=-0 \cdot 72 . \quad+$ Pooled regression coefficient $=+1 \cdot 56 . \quad \ddagger$ Pooled regression coefficient $=+0 \cdot 65$.

$100 \mathrm{ml}$. (as calculated above), it was found that significant differences existed between 15 of the 57 pairs, the glucose concentration being higher in the warmed foot in 13 pairs, and in the unwarmed foot in 2 pairs.

The results of the 4 cases where arterial blood samples were obtained are shown in Table III. The results for glucose concentration of blood from warmed and unwarmed feet in these 4 cases were not included in the statistical analysis above. Using the above criterion, significant differences were present between the triple results in several instances, but the glucose concentration was not always highest in the arterial sample nor lowest in the capillary sample from the unwarmed foot.

\section{Discussion}

Maternal and umbilical venous blood glucose concentrations. It is currently believed that maternal-foetal glucose transfer depends on an active transport mechanism rather than on simple diffusion (Chinard, Danesino, Hartmann, Huggett, Paul, and Reynolds, 1956; MacRae and Palavradji, 1964). Numerous investigators, including Morriss (1917), Slemons (1919), Naeslund (1928), Pedersen (1952), Spellacy, Goetz, Greenberg, and Ells (1964), have shown that the sugar concentration in maternal

\section{TABLE III}

Simultaneous Blood Glucose Estimations in Postnatal Period from (i) umbilical artery, (ii) heel-stab from warmed limb, (iii) heel-stab from unwarmed limb

\begin{tabular}{|c|c|c|c|}
\hline \multirow{3}{*}{ Patient } & \multicolumn{3}{|c|}{ Blood Glucose Concentration (mg./100 ml.) } \\
\hline & \multirow{2}{*}{ Arterial } & \multicolumn{2}{|c|}{ Capillary } \\
\hline & & Limb Warmed & $\underset{\text { Warmed }}{\text { Limb Not }}$ \\
\hline $\begin{array}{l}1 \text { (a)^ } \\
\text { (b) } \\
\text { 2(a) } \\
\text { (b) }\end{array}$ & $\begin{array}{r}147 \\
187 \\
65 \\
58\end{array}$ & $\begin{array}{r}137 \\
\frac{196}{60}\end{array}$ & $\begin{array}{r}128 \\
182 \\
46 \\
65\end{array}$ \\
\hline
\end{tabular}

* In fant No. 1 was on intravenous therapy. 
blood is higher than in umbilical venous blood at birth, though almost identical levels were reported by Bergsma (1912) and Holman and Mathieu (1934). In the present series the maternal plasma glucose concentration was higher than that in the umbilical vein by an average of $39.8 \mathrm{mg} . / 100 \mathrm{ml}$.

Ketteringham and Austin (1938) used JegherMyer's modification of Folin-Malmroos's micromethod, and Furuhjelm (1956) and Spellacy et al. (1964) used the Nelson and Somogyi method to show that the umbilical venous blood sugar concentration correlated well with the maternal blood sugar concentration at birth. In the present cases, where the glucose oxidase method was used, a similar close correlation was found.

A highly significant correlation between the sugar concentration in maternal venous blood and the concentration difference between maternal venous and umbilical venous blood was demonstrated by Furuhjelm (1956). In the present study the statistically preferable procedure of correlating the sums of the maternal and umbilical glucose concentrations with their differences was adopted, and no significant correlation was found.

Whether the transplacental transfer of glucose is by passive diffusion or by an active mechanism, the process will depend on normal placental function. In infants who are underweight at birth as a consequence of placental insufficiency, glucose transfer might be impaired, and under these circumstances the maternal-foetal blood glucose concentration gradient might be influenced. One would expect, if this were so, that for a given birthweight duration of gestation would have a significant effect on the glucose concentration gradient across the placenta. This was not so in the present series (partial correlation coefficient for glucose concentration gradient and duration of gestation with birthweight constant, $r_{D G . W}=0.248 ; p=0.1$ ), but it must be pointed out that few of the babies were unduly small for dates, only 3 falling within the 10th birthweight percentile for duration of gestation (using the Aberdeen figures discussed above). It would be of interest to compare, in normal and underweight infants, the concentration gradients across the placenta for a wide range of nutriments.

Effect of feeding regimen and hydrocortisone therapy on postnatal blood glucose concentration in 'underweight' infants. Early feeding of low birthweight infants such as was advocated by Smallpeice and Davies (1964) has more recently been shown by Wharton and Bower (1965) to be associated with an increased mortality rate. The former authors suggested that early feeding was advantageous to the 'small for dates' infant, while Wharton and Bower (1965) found more examples of symptomatic hypoglycaemia in their late feeding than in their early feeding group, and further noted among the 18 dysmature infants in their series that low blood sugar concentrations on the second day of life occurred more often with delayed feeding.

In the present series the three groups of 'underweight' infants all started feeds at 24 hours, while the volume and calorie intake were varied. The 'low calorie' group were given a calorie intake on the second and third days of life, which was lower than that used by Wharton and Bower (1965) for their 'later' fed infants, while the 'high calorie' group were given an intake above Wharton and Bower's 'later' fed infants but considerably less than their 'immediate' feeding group. The results of the study suggest that the higher calorie intake was associated with significantly higher concentrations of blood glucose over the first three days of life, and the only infant who developed symptomatic hypoglycaemia was in the low calorie group. The number of cases involved, however, is small, and the failure of the hydrocortisone group to show a regression coefficient for blood glucose similar to that of the high calorie group which was on the same diet suggests that a larger series should be studied. In future observations on low birthweight infants, whether premature or not, it will be necessary to study a range of feeding regimens between those used here and the early feeding advocated by Smallpeice and Davies (1964). It is advisable that frequent estimations of blood glucose concentrations are carried out over the first few days of such studies, since precise correlation between symptomatic and asymptomatic neonatal hypoglycaemia and later evidence of brain damage is not clear, though Wharton and Bower (1965) found such evidence only in their symptomatic cases. Meantime the feeding regimen for 'underweight' infants should provide a calorie intake at least as high as that of the high calorie diet given above, and it may be advisable to commence feeds on the first day. The above high calorie regimen has been well tolerated by over 30 'underweight' infants, none of whom has developed symptomatic hypoglycaemia. Hydrocortisone in the dosage used produced no significant rise in blood glucose concentration above that already produced by diet alone, and further evaluation of this form of therapy is necessary as regards both dosage and duration of administration.

Capillary blood glucose concentration in warmed and unwarmed feet. It was first suggested by Hagedorn (1920) that capillary blood 
was equivalent to arterial blood in sugar content, and Lundsgaard and Möller (1922) concluded from their observations on capillary and arterial blood oxygen concentrations that cutaneous blood should have the same sugar content as arterial blood. Since then it has been confirmed in the adult that capillary blood sugar concentration approximates to arterial blood sugar concentration (Foster, 1923; Langner and Fies, 1942; Somogyi, 1948), and studies on arteriovenous blood sugar concentration differences have been based on this assumption (Russell and Bruce, 1964). In the newborn infant, however, Cornblath et al. (1956) found a significant difference between the glucose concentration in arterial blood and that in the capillaries of a warmed foot in 7 of 16 cases studied. Both Foster (1923) and Somogyi (1948) recommended that the limb be warmed before capillary blood was obtained, but the object of this manœuvre was rather to increase the blood flow than to arterialize the blood. It has recently been demonstrated in infants with impaired skin circulation that the glucose concentration of capillary blood drawn from a heel-stab may be significantly lower than the glucose concentration of blood in the inferior vena cava (Stur, 1964).

Our findings indicate that in newborn infants the capillary blood glucose concentration may be significantly lower in samples obtained from unwarmed limbs than in samples from warmed limbs, even in the absence of obvious peripheral circulatory stasis, and the suggestion by Haworth (1965) that misleadingly low glucose levels may be found in capillary blood from infants with impaired skin circulation should te extended to all infants. The relation between capillary blood and arterial blood is variable, though it can reasonably be assumed that the glucose concentration of capillary blood from a warmed limb more closely approximates to that of arterial blood than does that of capillary blood from an unwarmed limb.

\section{Summary}

Plasma glucose concentrations were determined in maternal and umbilical venous blood samples. The two glucose concentrations were closely correlated, and the maternal was consistently higher than the umbilical by a mean of $39.8 \mathrm{mg} . / 100 \mathrm{ml}$. The maternal-umbilical glucose concentration gradient was significantly related to the duration of gestation, but not independently of birthweight.

The influence of diet on the blood glucose concentration of 30 infants whose birthweights were low for the period of gestation was studied. The blood glucose concentration was significantly raised over the first 3 days of life by a high calorie diet compared with a low calorie diet. The addition of intramuscular hydrocortisone medication to the high calorie regimen produced no significant effect on blood glucose concentration.

Prior warming of the feet significantly raised the glucose concentration of blood obtained by heel-stab in infants even in the absence of obvious peripheral circulatory stasis. It is recommended that the foot must always be warmed before withdrawing capillary blood for glucose estimation.

We are indebted to Professor R. G. Mitchell for permission to study infants under his care and for advice on the presentation of the results, and to Professor Sir Dugald Baird for access to the mothers. We thank also Dr. H. Thom for the glucose estimations, Mr. W. Z. Billewicz and Mr. G. A. Myers for statistical advice, Sister M. McKay for helping with the collection of blood specimens, and Sister M. Hogg for the preparation and administration of the feeds for the postnatal studies.

\section{REFERENCES}

Bergsma, E. (1912). Der Zuckerstoffwechsel in der Schwangerschaft und im Wochenbett. Ein Beitrag zur Frage der Schwangerschaftsleber. Z. Geburtsh. Gynäk., 72, 105.

Brown, R. J. K., and Wallis, P. G. (1963). Hypoglycaemia in the newborn infant. Lancet, $1,1278$.

Chinard, F. P., Danesino, V., Hartmann, W. L., Huggett, A. St. G., Paul, W., and Reynolds, S. R. M. (1956). The transmission of hexoses across the placenta in the human and the rhesus monkey (Macaca mulatta). F. Physiol. (Lond.), 132, 289.

Cornblath, M., Levin, E. Y., and Gordon, H. H. (1956). Studies of carbohydrate metabolism in the newborn. I. Capillaryvenous differences in blood sugar in normal newborn infants. Pediatrics, 18, 167.

—, Odell, G. B., and Levin, E. Y. (1959). Symptomatic neonatal hypoglycemia associated with toxemia of pregnancy. $\mathcal{F}$. Pediat., 55, 545.

—, Wybregt, S. H., Baens, G. S., and Klein, R. I. (1964) Symptomatic neonatal hypoglycemia: studies of carbohydrate metabolism in the newborn infant, VIII. Pediatrics, 33, 388.

Creery, R. D. G. (1963). Hypoglycaemia in the newborn. Lancet, $1,1423$.

Desmond, M. M. (1953). Observations related to neonatal hypoglycemia. F. Pediat., 43, 253.

Farquhar, J. W. (1956). The significance of hypoglycaemia in the newborn infant of the diabetic woman. Arch. Dis. Childh., 31, 203.

Foster, G. L. (1923). Studies on carbohydrate metabolism. I. Some comparisons of blood sugar concentrations in venous blood and in finger blood. F. biol. Chem., 55, 291.

Furuhjelm, U. (1956). Maternal and cord blood. A comparative investigation with reference to blood sugar, serum proteins, erythrocyte sedimentation rate and total serum lipids. Ann. Paediat. Fenn., Suppl. 5.

Hagedorn, H. C. (1920). Om sukkerprocenten i vena mediana cubiti. Ugeskr. Laeg., 82, 796. (Cited by Lundsgaard and Möller, 1922).

Hanley, B. J., and Horn, P. (1943). Comparative blood sugar studies in the parturient woman and the newborn infant. Amer. F. Obstet. Gynec., 46, 502.

Hartmann, A. F. (1955). Pathologic physiology in some disturbances of carbohydrate metabolism. F. Pediat., 47, 537. , and Jaudon, J. C. (1937). Hypoglycemia. ibid., 11, 1.

Haworth, J. C. (1965). Carbohydrate metabolism in the fetus and the newborn. Pediat. Clin. N. Amer., 12, 573.

- and Ford, J. D. (1960). Blood-sugar in infants after lactose feeds. Lancet, 2, 794.

- and - (1963). The effect of early and late feeding and glucagon upon blood sugar and serum bilirubin levels of premature babies. Arch. Dis. Childh., 38, 328. 
Hjelm, M., and de Verdier, C.-H. (1963). A methodological study of the enzymatic determination of glucose in blood. Scand. $\mathcal{F}$. clin. Lab. Invest., 15, 415.

- and Sjölin, S. (1965). The concentration of glucose in whole blood, plasma, and erythrocytes during the first week of life determined by different methods, and evaluation of the reliability of the methods. Acta paediat. scand., 54, 3.

Holman, A., and Mathieu, A. (1934). Blood chemistry studies of normal newborn infants. II. Blood sugar and alkali reserve estimations. Amer. F. Obstet. Gynec., 27, 95.

Kaye, R., Davidson, M. H., Williams, M. L., Kumagai, M., and Picou, D. M. (1961). The response of blood glucose, ketones, and plasma nonesterified fatty acids to fasting and epinephrine injection in infants and children. F. Pediat., 59, 836.

Ketteringham, R. C., and Austin, B. R. (1938). Blood sugar during labor, at delivery and postpartum, with observations on newborns. Amer. F. med. Sci., 195, 318.

Langner, P. H., Jr., and Fies, H. L. (1942). Blood sugar values of blood obtained simultaneously from the radial artery, antecubital vein, and the finger. Amer. F. clin. Path., 12, 559.

Lowrey, G. H., Graham, B. D., and Tsao, M. U. (1954). Chemical homeostasis in the newborn infants of diabetic mothers. Pediatrics, 13, 527.

Lundsgaard, C., and Möller, E. (1922). Investigations on the oxygen content of cutaneous blood (so-called capillary blood). F. exp. Med., 36, 559.

MacRae, D. J., and Palavradii, D. (1964). Some aspects of the transfer of glucose to the foetus. $\mathcal{F}$. Obstet. Gynaec. Brit. Cwlth, 71, 954.

Mason, H. H., and Andersen, D. H. (1941). Glycogen disease. Amer. F. Dis. Child., 61, 795.

McKittrick, J. B. (1940). Serial blood sugar determinations in normal newborn infants. F. Pediat., 16, 151.

Melichar, V., Novák, M., Hahn, P., and Koldovský, O. (1964). Free fatty acid and glucose in the blood of various groups of newborns. Preliminary report. Acta paediat. (Uppsala), 53, 343.

Morriss, W. H. (1917). The obstetrical significance of the bloodsugar with special reference to the placental interchange. Bull. fohns Hopk. Hosp., 28, 140.

Naeslund, J. (1928). Investigations into the transit of reducing substances from mother to foetus in alimentary hyperglycaemia. Acta obstet. gynec. scand., 7, 25.
Neligan, G. A. (1964a). Hypoglycaemia in the newborn. Proc. roy. Soc. Med., 57, 1059.

- (1964b). Hypoglycaemia in the newborn infant. In Nutricia Symposium on the Adaptation of the Newborn Infant to Extrauterine Life, ed. J. H. P. Jonxis, H. K. A. Visser, and J. A. Troelstra, p. 42. H. E. Stenfert Kroese, Leyden.

- (1965). Idiopathic hypoglycaemia in the newborn. In Recent Advances in Paediatrics, 3rd ed., ed. D. Gairdner, p. 110. Churchill, London.

-, Robson, E., and Watson, J. (1963). Hypoglycaemia in the newborn. A sequel of intrauterine malnutrition. Lancet, 1 , 1282.

Norval, M. A., Kennedy, R. L. J., and Berkson, J. (1949). Blood sugar in newborn infants. $\mathcal{F}$. Pediat., 34, 342.

Pedersen, J. (1952). Diabetes and Pregnancy. Blood Sugar of Newborn Infants. Danish Science Press, Copenhagen.

Russell. G. F. M., and Bruce, J. T. (1964). Capillary-venous glucose differences in patients with disorders of appetite. Clin. Sci., 26, 157.

Shelley, H. J. (1964). Carbohydrate reserves in the newborn infant. Brit. med. $f_{\text {., }} 1,273$.

Sherman, H. (1947). Islet cell tumor of pancreas in a newborn infant (nesidioblastoma). Amer. F. Dis. Child., 74, 58.

Slemons, J. M. (1919). The nutrition of the fetus. Amer. f. Obstet. Dis. Wom., 80, 194.

Smallpeice, V., and Davies, P. A. (1964). Immediate feeding of premature infants with undiluted breast-milk. Lancet, 2, 1349.

Somogyi, M. (1948). Studies of arteriovenous differences in blood sugar. I. Effect of alimentary hyperglycemia on the rate of extrahepatic glucose assimilation. F. biol. Chem., 174, 189.

Spellacy, W. N., Goetz, F. C., Greenberg, B. Z., and Ells, J. (1964). The human placental gradient for plasma insulin and blood glucose. Amer. F. Obstet. Gynec., 90, 753.

Stur, O. (1964). Studies on the physiologic hypoglycemia of newborns. Biol. Neonat. (Basel), 6, 38.

Tynan, M. J., and Haas, L. (1963). Hypoglycaemia in the newborn.

Lancet, 2, 90.
Wachter, H. E. (1949). Hypoglycemia of the newborn infant. $\bigcirc \overrightarrow{0}$ F. Mo. med. Ass., 46, 837.

Wharton, B. A., and Bower, B. D. (1965). Immediate or later feeding for premature babies ? A controlled trial. Lancet, 2 , 969. 